\title{
Multi-objective Optimization of Hard Milling Using Taguchi Based Grey Relational Analysis
}

\author{
Djordje CICA, Halil CALISKAN, Peter PANJAN, Davorin KRAMAR
}

\begin{abstract}
The influence of hard coatings and machining parameters, in particular cutting speed, feed per tooth and depth of cut on specific cutting energy, productivity and surface quality in milling of hardened cold work tool steel, were investigated in this paper. Taguchi's design of experiments was employed for planning of experiments using $L_{27}$ orthogonal array. Optimal setting of machining parameters for multi-objective characteristics was determined using grey relational analysis. The principal component analysis was used to define the corresponding weight factors of each quality characteristics under optimization. Analysis of variance was conducted and it was revealed that feed per tooth is the most significant parameter affecting quality characteristics. Finally, results of confirmation test with the optimal machining parameters settings have shown that the proposed model improves overall performance of hard milling process.
\end{abstract}

Keywords: grey relational analysis; hard milling; optimization; Taguchi

\section{INTRODUCTION}

Hard machining has been extensively used in the past few decades as an alternative to the common methods of machining the hardened materials which include grinding and electrical discharge machining. Compared to the other methods, milling of the hardened materials provides increased productivity and flexibility. The cost and quality of machined parts as well as productivity are highly sensitive to the machining parameters, in particular depth of cut, cutting speed, feed rate, tool geometry etc. Therefore, state-of-the-art machine tools require methodology for the selection of optimal machining parameters subjected to a set of defined technological constraints. Optimization of machining parameters through advanced methods is typically based on optimizing certain criteria (quality of the product, maximum production rate, minimum time of production, minimum cost of production) which are subjected to a set of constraints (machine tool specifications and dynamics, cutting tool specifications and dynamics, machined part design requirements) [1-4]. The decision of optimal machining parameters is commonly considered as constrained nonlinear programming problem with high computational demands.

The selection of optimal process parameters in milling has been investigated by many researchers. There are few researches that have used optimization technique based on the Taguchi method [5-7]. In order to optimize the complicated relationships among multiple performance characteristics some researchers apply grey system theory. Chang and Lu [8] optimize machined surface accuracy in side milling process by using the grey relational analysis (GRA). Tsao [9] successfully applied grey-Taguchi method for optimization the milling process parameter of aluminium alloy. In this research, the multiple quality characteristics were tool wear and surface finish. Gopalsamy et al. [10] obtain optimal process parameters for rough as well as finish machining operations using GRA and applied analysis of variance to identify the effect of machining factors on multiple responses, i.e. material removal rate, surface roughness, tool life and tool wear. Lu et al. [11] proposed use of GRA combined with principal component analysis (PCA) for improving the performances of rough cutting in end milling. Three objectives (material removal rate, flank wear rate of end cutting and peripheral cutting edge) were simultaneously optimized. Yan and Li [12] applied GRA and response surface methodology to optimize milling process parameters with the purpose to improve the sustainable machining. In this study, cutting energy, surface roughness and material removal rate were selected as performance indexes to optimize the milling parameters. Kant and Sangwan [13] used GRA coupled with PCA to minimize surface roughness and power consumption in milling AISI 1045 steel. Shi et al. [14] utilized Taguchi with GRA in order to determine an optimum combination of machining factors to enhance the surface roughness and the hardness of dry milling magnesium alloy. Varghese et al. [15] also used a Taguchi-based GRA to determine optimum cutting condition in cryo-milling. The cutting forces and surface roughness were selected as objective functions.

As complexity of machining processes increased substantially, researchers have focused on artificial intelligence (AI) optimization techniques. The findings of the literature review show that genetic algorithm (GA) was extensively applied by most researchers to optimize the milling process parameters [16-22]. Many researchers have proposed other AI techniques based on the particle swarm optimization [23-26], artificial bee colony [27], etc.

The review of literature on optimization of milling operations acknowledges the fact that most work is primarily dedicated to the single objective optimization only, i.e. surface roughness, production costs, tool life, cutting energy, machining time, etc. However, the optimization of hard milling represents a multi-objective optimization problem. Only a very few research efforts have been realized to study the influence of milling parameters simultaneously. In modern environmentally friendly manufacturing, the need to diminish energy consumption cost becomes one of the most important challenges. At the same time, it is crucial to enhance production rate and improve the surface quality. For meeting these challenges, this study presents a multiobjective optimization model in regard to trade-offs between energy consumption, productivity and surface quality. As such optimization of the machining parameters, which include the influence of hard coatings and three cutting parameters, namely cutting speed, feed per tooth, and depth of cut, on three performance outputs-specific 
cutting energy $(S C E)$, material removal rate $(M R R)$ and surface roughness $(S R)$ in dry hard milling of cold work tool steel can be considered as a new contribution in this area.

\section{EXPERIMENTAL METHODS \\ 2.1 Design of Experiments}

With the objective to investigate the degree of influence of four process parameters including coating $(A)$, cutting speed $(B)$, feed per tooth $(C)$, and depth of cut $(D)$ in milling, three levels of each factor were chosen, and an $L_{27}\left(3^{13}\right)$ orthogonal array was selected. With the purpose to enable high productivity, the cutting parameters used during the experimental tests were selected as high as possible. The three levels of each design factor are distinguished by numbers 1,2 , and 3 (Tab. 1).

Table 1 Control factors and their levels

\begin{tabular}{|c|c|c|c|c|}
\hline \multirow{2}{*}{ Lev. } & Coating - A & $\begin{array}{c}\text { Cutting } \\
\text { speed }-B \\
/ \mathrm{m} / \mathrm{min}\end{array}$ & $\begin{array}{c}\text { Feed per } \\
\text { tooth }-C \\
/ \mathrm{mm} / \mathrm{t}\end{array}$ & $\begin{array}{c}\text { Depth of } \\
\text { cut }-D \\
/ \mathrm{mm}\end{array}$ \\
\hline 1 & AlTiN/TiN & 50 & 0.1 & 0,50 \\
\hline 2 & TiN/TiAlN & 100 & 0.3 & 0,75 \\
\hline 3 & TiAlSiN/TiSiN/TiAlN & 150 & 0.5 & 1,00 \\
\hline
\end{tabular}

\subsection{Experimental Setup and Material}

Three-axis CNC vertical milling machine tool Mori Seiki Frontier-M was used for experimentation. All the machining tests were realized under dry conditions. The cutting tools, used during machining tests, were carbide triangular carbide inserts. Different kinds of coatings, involving AlTiN / TiN, and TiAlSiN / TiSiN / TiAlN were deposited on the carbide inserts to improve the mechanical properties, whereas TiN / TiAlN coatings were provided by SECO tools. For the purpose of strengthening the cutting edge all cutting tools have a $32^{\circ}$ chamfer.

The tools were mounted on a SECO tool holder including the cutting diameter of $21 \mathrm{~mm}$ and with two teeth to provide values of $0^{\circ}, 6^{\circ}$ and $6^{\circ}$ for radial rake, axial rake and flank angle, respectively. The width of cut was 12,8 $\mathrm{mm}$. AISI O2 steel specimens of $132 \times 100 \mathrm{~mm}$ and $50 \mathrm{~mm}$ thickness were used in the experimental study. This material has an extensive application area in industry due to excellent resistance to cracking, high dimensional stability at elevated temperatures and good wear resistance. However, this material has hardness of $\sim 61 \mathrm{HRC}$ and therefore is considered as hard to machine material.

\subsection{Measurement Procedure}

In this study, the optimization of hard milling operation concerning four machining parameters (coating, cutting speed, feed per tooth, and depth of cut) was sought. With the aim to have pertinent data to estimate the effects of above mentioned parameters upon the performance measures such as specific cutting energy, material removal rate and surface roughness, the face milling tests were carried out as a case study by using the proposed experimental setup. The illustration of the steps carried out in this research is given in Fig. 1.

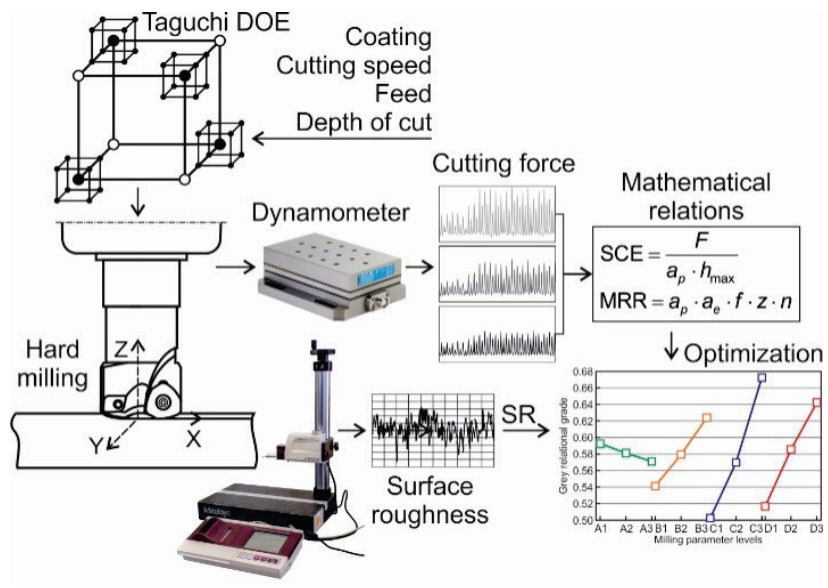

Figure 1 Schematic diagram of the experimental setup and modelling procedure

A three-axis Kistler 9259A dynamometer, a charge amplifier Kistler 5001, and a data acquisition hardware were adopted to measure the cutting force components $\left(F_{x}\right.$, $F_{y}$ and $F_{z}$ ). For data analysis and visualization, a software LabVIEW was used. Signals captured from the threecomponent dynamometer were amplified and afterwards transmitted to personal computer. The workpiece was rigidly positioned on a dynamometer in order to ensure precise measurement of cutting force components. With the purpose of obtaining complete stabilization as well as avoiding the transient state measurements of cutting force components were initiated after the tool holder had wholly entered the workpiece. The specific cutting energy was computed from the cutting force and milling parameters by using Eq. (1) [28]:

$$
S C E=\frac{F}{a_{p} \cdot h_{\max }}
$$

where $F$ is cutting force, $a_{p}$ is axial depth of cut, $h_{\max }$ is maximal undeformed chip thickness of a cutting position.

The most frequently used optimization criterion of productivity in milling process is material removal rate which can be computed by using Eq. (2):

$M R R=a_{p} \cdot a_{e} \cdot f \cdot z \cdot n$

where $a_{e}$ is width of cut, $f$ is feed per tooth, $z$ is cutter teeth number and $n$ is spindle speed.

The surface roughness of the machined surface was measured using a SJ-301 Mitutoyo profilometer along the feed direction. Every measurement was repeated at least three times, and the average values of these measurements were saved for use in developing the optimization model.

The measured values of the three response variables are given in Tab. 2 .

\section{TAGUCHI METHOD}

Taguchi method, originally developed by Taguchi [29], is extensively applied in engineering design and analysis because of its simplicity and effectiveness. This method employs specially constructed tables known as orthogonal array. In Taguchi method, estimation of deviation between the experimental and the optimal values is based on a loss function which transforms the original 
data to the signal to noise $(\mathrm{S} / \mathrm{N})$ ratio. $\mathrm{S} / \mathrm{N}$ ratio is a statistical measure of performance which represents ratio of the mean (desirable value) to the standard deviation (undesirable value). Thus, $\mathrm{S} / \mathrm{N}$ ratio is utilized for the determination of the optimal product/process parameter settings. Usually, there are three standard categories of S / $\mathrm{N}$ ratios available depending upon the objective of the performance characteristic: smaller-the-better Eq. (3), larger-the-better Eq. (4) and nominal-the-better Eq. (5):

$$
\begin{aligned}
& \eta_{j}=-10 \log \left(\frac{1}{n} \sum_{i=1}^{n} y_{i}^{2}\right) \\
& \eta_{j}=-10 \log \left(\frac{1}{n} \sum_{i=1}^{n} \frac{1}{y_{i}^{2}}\right) \\
& \eta_{j}=10 \log \left(\frac{\bar{y}}{s_{y}^{2}}\right)
\end{aligned}
$$

where: $y_{i}$ and $\bar{y}$ are the observed data and the average of observed data, respectively, $n$ is the number of observations and $s_{y}{ }^{2}$ is the variance of the observed data.

In addition to the $\mathrm{S} / \mathrm{N}$ ratio, a statistical analysis of variance (ANOVA) is usually performed to indicate the degree of significance of experimental design parameters on the quality characteristic.

The original Taguchi method has been extensively utilized in engineering analysis for single response optimization. Therefore, it is necessary to modify this method for multiple performance characteristics optimization. Several modifications of the original Taguchi method for multi-objective optimization can be found in many research papers. Probably most popular method is grey-Taguchi method which combines original Taguchi method with grey relational analysis.

\section{GREY RELATIONAL ANALYSIS}

Grey relational analysis (GRA) is probably one of the most influential application areas of grey system theory originally proposed by Deng [30]. GRA is efficient method for converting a multi-objective problem with complicated relations between variables into single-objective problem.

The first step in GRA involves data normalization (data pre-processing) into a predefined range $(0,1)$ by reason of the inconsistent measurement units. This procedure is termed the grey relational generation. In concordance with the characteristics of a data sequence, there are three different types of data normalization, i.e. the lower-the-better, the higher-the-better, and the nominalthe-better, expressed by Eq. (6), Eq. (7) and Eq. (8), respectively:

$$
\begin{aligned}
& X_{i}^{*}(k)=\frac{\max X_{i}(k)-X_{i}(k)}{\max X_{i}(k)-\min X_{i}(k)} \\
& X_{i}^{*}(k)=\frac{X_{i}(k)-\min X_{i}(k)}{\max X_{i}(k)-\min X_{i}(k)} \\
& X_{i}^{*}(k)=1-\frac{\left|X_{i}(k)-X_{o b}(k)\right|}{\max X_{i}(k)-\min X_{i}(k)}
\end{aligned}
$$

where $X_{i}^{*}(k)$ and $X_{i}(k)$ refers to the normalized value and experimental result of the $k^{\text {th }}$ performance characteristic in the $i^{\text {th }}$ experiment, respectively, whereas $\max X_{i}(k)$ and min $X_{i}(k)$ are the largest and smallest value of $X_{i}(k)$, respectively, and $X_{o b}(k)$ represent the target of $X_{i}(k)$.

The second step involves the determination of the grey relational coefficients (GRCs) from the normalized experimentation data. GRC is a quantity which expresses the relationship between reference and real experimental normalized data and can be calculated as follows:

$$
\xi_{i}(k)=\frac{\Delta_{\min }+\zeta \Delta_{\max }}{\Delta_{0 i}+\zeta \Delta_{\max }}
$$

where $\Delta_{0 i}(k)=\left|X_{0}{ }^{*}(k)-X_{\mathrm{i}}^{*}(k)\right|$ is the absolute value of two comparative sequences, $\zeta$ is the identification or distinguishing coefficient, $\Delta_{\min }$ is minimum value of $\Delta_{0 i}$, $\Delta_{\max }$ is maximum value of $\Delta_{0 i}$. In this paper, identification coefficient was set to 0,5 which is common value for most situations.

Finally, computation of the grey relational grade (GRG) represents the last step of GRA. The GRG is calculated by averaging the weighted GRCs corresponding to each quality characteristic. GRG is computed using the following equation:

$\gamma_{i}=\frac{1}{n} \sum_{k=1}^{n} w_{k} \xi_{i}(k), \sum_{k=1}^{n} w_{k}=1$

where $n$ is the number of performance characteristics and $w_{k}$ is weight factor which relates to importance of each response in multi-objective problem.

The GRG is indicator of correlation among the reference sequence and the comparability sequence. Hence, higher GRG implies that the particular comparability sequence is closer to the reference sequence.

\section{PRINCIPAL COMPONENT ANALYSIS}

Principal component analysis (PCA) was firstly proposed by Pearson [31]. PCA was primarily designed to clarify the structure of variance-covariance by way of the linear combinations of each performance characteristic. The procedure is explained as follows:

1) The original multiple quality characteristic array:

$$
\begin{gathered}
x_{i}(j), \quad i=1,2, \ldots, m ; \\
X=\left[\begin{array}{cccc}
x_{1}(1) & x_{1}(2) & \ldots & x_{1}(n) \\
x_{2}(1) & x_{2}(2) & \cdots & x_{2}(n) \\
\vdots & \vdots & \ddots & \vdots \\
x_{m}(1) & x_{m}(2) & \cdots & x_{m}(n)
\end{array}\right]
\end{gathered}
$$

where $m$ is the number of test trial, while $n$ is the number of the quality characteristic. In this study, $X$ is the GRC of each quality characteristic.

2) Correlation coefficient array:

$$
R_{j l}=\left(\frac{\operatorname{Cov}\left(x_{i}(j), x_{i}(l)\right)}{\sigma_{x_{i}}(j) \times \sigma_{x_{i}}(l)}\right)
$$


where $\operatorname{Cov}\left(x_{i}(j), x_{i}(l)\right)$ is the covariance, while $\sigma_{x i}(j)$ and $\sigma_{x i}(l)$ are the standard deviation of response variables $x_{i}(j)$ and $x_{i}(l)$, respectively.

3) Determination of the eigenvalues and corresponding eigenvectors.

These parameters are calculated from Eq. (12) as follows:

$$
\left(R-\lambda_{k} I_{m}\right) V_{i k}=0
$$

where $\lambda_{k}$ are eigenvalues, $\sum_{k=1}^{n} \lambda_{k}=n, k=1,2, \ldots, n$, and $V_{i k}=\left[a_{k 1}, a_{k 2}, \ldots, a_{k n}\right]^{\mathrm{T}}$ are corresponding eigenvectors.

4) Evaluating principal components.

The principal components are defined as:
$Y_{m k}=\sum_{i=1}^{n} x_{m}(i) \cdot V_{i k}$

where $Y_{m 1}, Y_{m 2}$ are known as first principal component, second principal component and so on.

These components are created in order of decreasing variance, and consequently, the first principal component $Y_{m 1}$ accounting for the greatest amount of the variance in the data.

\section{RESULTS AND DISCUSSION}

The performance characteristics obtained from experimental data were first converted into $\mathrm{S} / \mathrm{N}$ ratio.

Table 2 Taguchi's $L 27$ orthogonal array, the measured values of the responses, grey relational coefficients and grey relational grade

\begin{tabular}{|c|c|c|c|c|c|c|c|c|c|c|c|}
\hline & \multicolumn{7}{|c|}{ Machining param. } & \multicolumn{3}{|c|}{ Responses } & \multicolumn{2}{|c|}{ GRC } & \multirow{2}{*}{ GRG } \\
\hline No. & $A$ & $B$ & $C$ & $D$ & $S C E / \mathrm{J} / \mathrm{mm}^{3}$ & $M R R / \mathrm{mm}^{3} / \mathrm{s}$ & $S R / \mu \mathrm{m}$ & $\xi_{1}(k)$ & $\xi_{2}(k)$ & $\xi_{3}(k)$ & 0,366 \\
\hline 1. & 1 & 1 & 1 & 1 & 19,84 & 16,2 & 0,33 & 0,3335 & 0,3333 & 0,4414 & 0,3291 \\
\hline 2. & 1 & 1 & 2 & 2 & 8,65 & 72,8 & 0,44 & 0,6763 & 0,4916 & 0,3891 & 0,5291 \\
\hline 3. & 1 & 1 & 3 & 3 & 7,18 & 161,7 & 0,36 & 0,879 & 0,6574 & 0,4242 & 0,5291 \\
\hline 4. & 1 & 2 & 1 & 2 & 16,12 & 48,5 & 0,12 & 0,382 & 0,4357 & 0,8381 & 0,5373 \\
\hline 5. & 1 & 2 & 2 & 3 & 7,89 & 194 & 0,21 & 0,7632 & 0,7122 & 0,5598 & 0,6851 \\
\hline 6. & 1 & 2 & 3 & 1 & 7,96 & 161,7 & 0,55 & 0,7539 & 0,6574 & 0,3563 & 0,6022 \\
\hline 7. & 1 & 3 & 1 & 3 & 12,56 & 97 & 0,11 & 0,4627 & 0,5406 & 0,9082 & 0,6228 \\
\hline 8. & 1 & 3 & 2 & 1 & 10,35 & 145,5 & 0,35 & 0,5534 & 0,6293 & 0,4296 & 0,5409 \\
\hline 9. & 1 & 3 & 3 & 2 & 6,93 & 363,8 & 0,56 & 0,9322 & 1 & 0,3539 & 0,7798 \\
\hline 10. & 2 & 1 & 1 & 1 & 19,43 & 16,2 & 0,19 & 0,3378 & 0,3333 & 0,5951 & 0,414 \\
\hline 11. & 2 & 1 & 2 & 2 & 9,29 & 72,8 & 0,41 & 0,6214 & 0,4916 & 0,4007 & 0,5122 \\
\hline 12. & 2 & 1 & 3 & 3 & 6,71 & 161,7 & 0,41 & 0,9865 & 0,6574 & 0,4007 & 0,7018 \\
\hline 13. & 2 & 2 & 1 & 2 & 14,23 & 48,5 & 0,18 & 0,4184 & 0,4357 & 0,6162 & 0,4838 \\
\hline 14. & 2 & 2 & 2 & 3 & 8,12 & 194 & 0,42 & 0,7338 & 0,7122 & 0,3967 & 0,6249 \\
\hline 15. & 2 & 2 & 3 & 1 & 8,16 & 161,7 & 0,51 & 0,729 & 0,6574 & 0,3667 & 0,5961 \\
\hline 16. & 2 & 3 & 1 & 3 & 13,11 & 97 & 0,1 & 0,4465 & 0,5406 & 1 & 0,6445 \\
\hline 17. & 2 & 3 & 2 & 1 & 11,02 & 145,5 & 0,4 & 0,5203 & 0,6293 & 0,405 & 0,5212 \\
\hline 18. & 2 & 3 & 3 & 2 & 7,75 & 363,8 & 0,48 & 0,7828 & 1 & 0,3756 & 0,731 \\
\hline 19. & 3 & 1 & 1 & 1 & 19,86 & 16,2 & 0,16 & 0,3333 & 0,3333 & 0,6675 & 0,4342 \\
\hline 20. & 3 & 1 & 2 & 2 & 9,33 & 72,8 & 0,25 & 0,6184 & 0,4916 & 0,5073 & 0,5433 \\
\hline 21. & 3 & 1 & 3 & 3 & 6,66 & 161,7 & 0,47 & 1 & 0,6574 & 0,3788 & 0,7002 \\
\hline 22. & 3 & 2 & 1 & 2 & 16,38 & 48,5 & 0,16 & 0,3777 & 0,4357 & 0,6675 & 0,4842 \\
\hline 23. & 3 & 2 & 2 & 3 & 8,57 & 194 & 051 & 0,6842 & 0,7122 & 0,3667 & 0,5975 \\
\hline 24. & 3 & 2 & 3 & 1 & 8,39 & 161,7 & 0,37 & 0,7029 & 0,6574 & 0,419 & 0,6023 \\
\hline 25. & 3 & 3 & 1 & 3 & 13,24 & 97 & 0,17 & 0,4429 & 0,5406 & 0,64 & 0,5344 \\
\hline 26. & 3 & 3 & 2 & 1 & 9,96 & 145,5 & 0,25 & 0,5758 & 0,6293 & 0,5073 & 0,5344 \\
\hline 27. & 3 & 3 & 3 & 2 & 8,95 & 363,8 & 0,66 & 0,6489 & 1 & 0,3333 & 0,6686 \\
\hline
\end{tabular}

In hard milling process, lower values of specific cutting energy as well as surface roughness are indicators of better response characteristic. Therefore, for these responses smaller-the-better criterion has been selected. On the contrary, larger-the-better criterion was chosen for $M R R$ since this response should be maximized. In relation to the procedural steps of Taguchi based GRA, the S / N ratios were normalized by using Eq. (7). Thereafter, GRCs for each performance characteristics was calculated using Eq. (9) and listed in Tab. 2. These GRCs are further used to evaluate GRG Eq. (10). Usually, researchers assign an equal weight to different responses in order to calculate the GRG of multiple performance characteristic or subjectively select the weights $[8,9,10,14]$. With the purpose of objectively considering relative importance for each quality characteristic, PCA was introduced to assign adequate weight factors. GRCs of each response from Tab. 2 were used to determine the correlation coefficient matrix and calculate the respective eigenvalues (Tab. 3). In Tab. 4 are listed the eigenvectors associated to each eigenvalue. The variance contribution for the first principal component describing the three quality characteristics is $74,36 \%$.
Hence, the contribution of the corresponding quality characteristic to the principal component is represented by its square. Thus, the squares of its related eigenvectors were chosen as the weighting factors of the associated quality characteristic, and the coefficients $w_{1}, w_{2}$ and $w_{3}$ in Eq. (10) are consequently set as 0,3704; 0,3276 and 0,3020 respectively. Based on Eq. (10) and the GRCs, the GRG was calculated and shown in Tab. 2.

Table 3 The eigenvalues and explained variation for principal components

\begin{tabular}{|c|c|c|}
\hline Principal component & Eigenvalue & Explained variation / \% \\
\hline First & 2,2308 & 74,36 \\
\hline Second & 0,4986 & 16,62 \\
\hline Third & 0,2706 & 9,02 \\
\hline
\end{tabular}

Afterwards, on the basis of the average value of GRG, the response table as well as response graph for each level of the process parameters were constructed. The optimal setting of machining parameter corresponds to level with higher value of GRG. Based on results presented in Tab. 5 and Fig. 2 the optimal level setting of selected machining parameters is $A 1 B 3 C 3 D 3$ for minimizing the specific 
cutting energy, increase productivity and improve surface quality.

Table 4 The eigenvectors for the principal components

\begin{tabular}{|c|c|c|c|}
\hline \multirow{2}{*}{ Performance characteristic } & $\begin{array}{c}\text { First } \\
\text { principal } \\
\text { component }\end{array}$ & $\begin{array}{c}\text { Second } \\
\text { principal } \\
\text { component }\end{array}$ & $\begin{array}{c}\text { Third } \\
\text { principal } \\
\text { component }\end{array}$ \\
\hline Specific cutting energy $(S C E)$ & 0,6086 & 0,1193 & $-0,7844$ \\
\hline Material removal rate $(M R R)$ & 0,5723 & 0,6187 & 0,5382 \\
\hline Surface roughness $(S R)$ & $-0,5495$ & 0,7765 & $-0,3083$ \\
\hline
\end{tabular}

Table 5 Response table for the grey relational grade

\begin{tabular}{|c|c|c|c|c|}
\hline \multirow{2}{*}{$\begin{array}{c}\text { Machining } \\
\text { parameter }\end{array}$} & Level 1 & Level 2 & Level 3 & \multirow{2}{*}{ Max - min } \\
\hline$A$ & 0,5925 & 0,5811 & 0,5708 & 0,0217 \\
\hline$B$ & 0,5411 & 0,5793 & 0,6240 & 0,0829 \\
\hline$C$ & 0,5024 & 0,5696 & 0,6723 & 0,1699 \\
\hline$D$ & 0,5166 & 0,5855 & 0,6423 & 0,1257 \\
\hline \multicolumn{4}{|l}{ Total mean value of GRG $\eta_{0}=0,5815$} \\
\hline
\end{tabular}

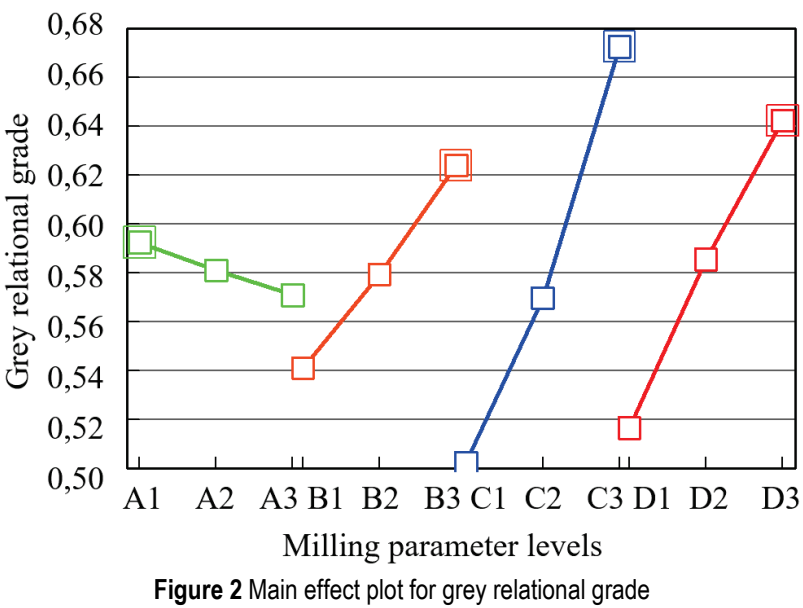

Figure 2 Main effect plot for grey relational grade

$\begin{array}{lllllllll}\text { B1 } & \text { B2 } & \text { B3 } & \text { C1 } & \text { C2 } & \text { C3 } & \text { D1 } & \text { D2 } & \text { D3 }\end{array}$

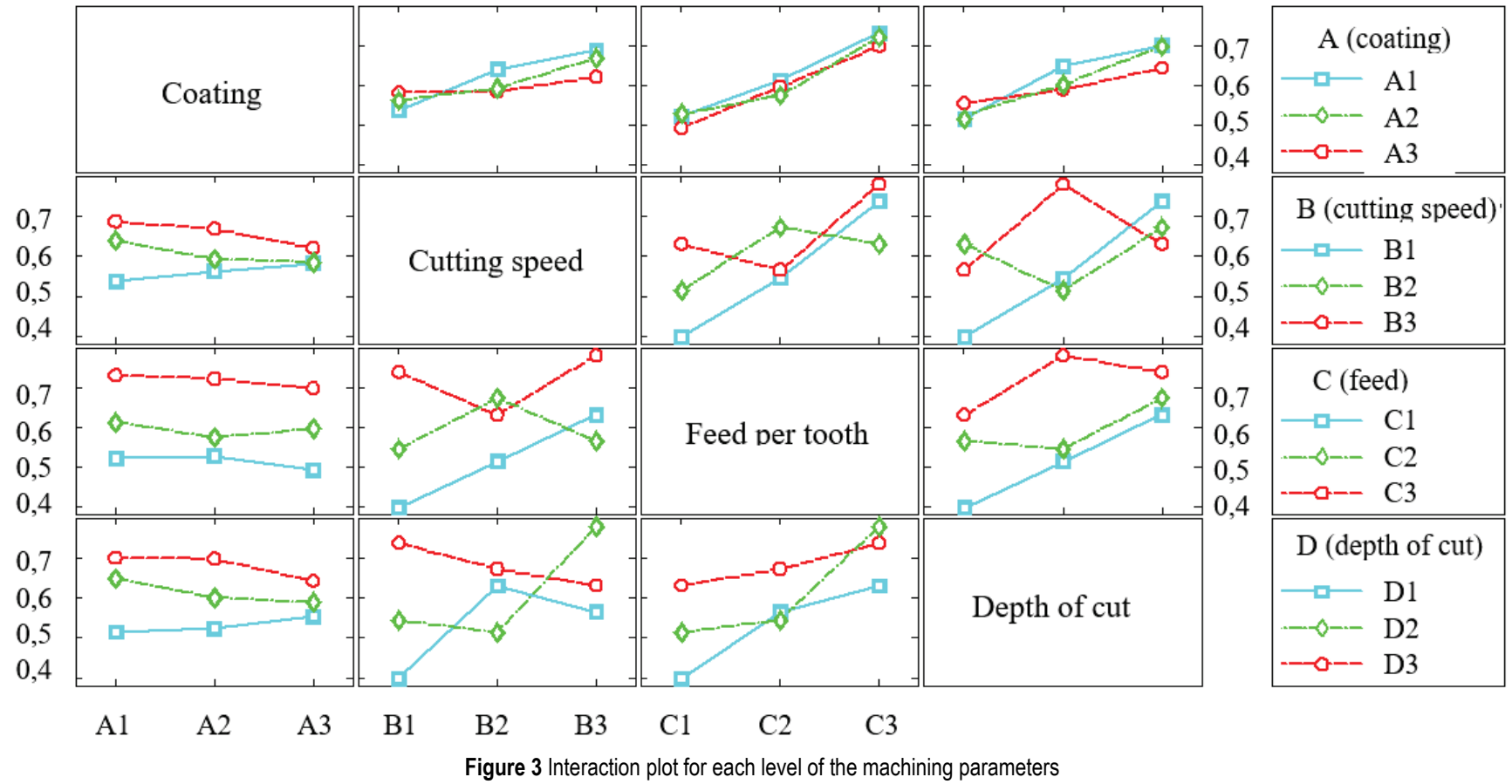

Table 6 Results of the ANOVA

\begin{tabular}{|c|c|c|c|c|c|c|}
\hline Parameter & DOF & SS & MS & $F$-ratio & $P$-value & PC \\
\hline A & 2 & 0,00211 & 0,0011 & 0,84 & 0,4472 & 0,8 \\
\hline B & 2 & 0,03097 & 0,0155 & 12,33 & 0,0004 & 12 \\
\hline C & 2 & 0,13191 & 0,0660 & 52,52 & 0 & 51 \\
\hline D & 2 & 0,07126 & 0,0356 & 28,37 & 0 & 27,5 \\
\hline Error & 18 & 0,02261 & 0,0013 & & & 8,7 \\
\hline Total & 26 & 0,25887 & & & & 100 \\
\hline
\end{tabular}

Furthermore, an analysis of variance was performed to examine the influence of each machining parameter on the multi-performance characteristics. The results of ANOVA are shown in Tab. 6, indicating the sources of variation, their degrees of freedom (DOF), the total sum of squares (SS), the mean squares (MS), Fisher's ratio ( $F$-ratio), probability value ( $P$-value) and percent of contribution (PC). ANOVA was carried out at a 95\% confidence level $\alpha=0,05$ (the level of significance is 0,05 ). Thus, the parameters with a $P$-value less than 0,05 are considered to be statistically significant. According to Tab. 6, it can be noticed that factor $C$ (feed per tooth) is the most significant parameter. The next significant parameter is factor $D$ (depth of cut) followed by factor $B$ (cutting speed). The factor $A$ (coating) is the least influencing factor when compared with other machining parameters.

The interaction plot between the four input machining parameters under study over the calculated GRG is shown in Fig. 3. A lower level of interaction is noticed between coating and cutting speed for all level values of cutting speed. A moderate level of interaction exists among cutting speed and feed per tooth, whereas a higher level of interaction is observed among cutting speed and depth of cut for all levels. For higher values of feed per tooth, an obvious interaction effect is found between feed per tooth and depth of cut. In between depth of cut and coating a moderate interaction effect is noticed for all levels.

The last step of GRA is to prove the improvement of the quality characteristics at the optimal level of designed process parameters. The estimated GRG at the optimal level of the machining parameters can be determined as: 


$$
\hat{\eta}=\eta_{m}+\sum_{i=1}^{n}\left(\bar{\eta}_{i}-\eta_{m}\right)
$$

where $\hat{\eta}$ is the estimated GRG at optimal level, $\eta_{m}$ is the total mean of the GRG, $\bar{\eta}_{i}$ is the mean GRG at the preferred level and $n$ is the number of the machining parameters influencing the multiple performance characteristic.

Using the optimal settings of milling parameters $(A 1 B 3 C 3 D 3)$ the estimated value of grey relational grade calculated from Eq. (15) was 0,7867, while the response values were as follows: $S C E=5,27 \mathrm{~J} / \mathrm{mm}^{3}, M R R=301,8$ $\mathrm{mm}^{3} / \mathrm{s}$ and $S R=0,46 \mu \mathrm{m}$. Hence, confirmation test reveals that the proposed optimization method improves overall performance of milling process.

\section{CONCLUSION}

In this article, a multi-objective optimization of hard milling parameters using a Taguchi based grey relational analysis was presented. The $L_{27}\left(3^{13}\right)$ orthogonal array was chosen as experimental design for the four machining parameters: coating, cutting speed, feed per tooth and depth of cut. The specific cutting energy, $M R R$ and surface roughness were selected to be the quality responses. Grey relational analysis was used to identify the optimal level setting of input process parameters for minimizing the specific cutting energy and surface roughness, and for maximizing material removal rate, whereas principal component analysis was utilized to assign appropriate weight factor to each response variable. The following conclusions can be summarized:

- Taguchi based GRA based optimization revealed that a AlTiN/TiN coating, cutting speed of $150 \mathrm{~m} / \mathrm{min}$, a feed per tooth of $0,5 \mathrm{~m} /$ tooth, and a depth of cut of $1 \mathrm{~mm}$ are the optimal combination of milling parameters.

- ANOVA indicated that feed per tooth had the largest significant effect $(51,0 \%)$ on the multiple performance characteristic, followed by depth of cut $(27,5 \%)$, cutting speed $(12,0 \%)$ and coating $(0,8 \%)$.

- The confirmation experiment indicates that the specific cutting energy, MRR and surface quality can simultaneously be improved by using Taguchi based GRA.

The proposed methodology utilized in this study can be used by production engineers in order to improve productivity and produce quality parts. In the future, this research can be extended to the machinability investigations under different cooling conditions. In addition, the responses such as tool life, cutting temperature and surface morphologies can be investigated and optimized.

\section{REFERENCES}

[1] Sekulic, M., Pejic, V., Brezocnik, M., Gostimirovic, M., \& Hadzistevic, M. (2018). Prediction of surface roughness in the ball-end milling process using response surface methodology, genetic algorithms, and grey wolf optimizer algorithm, Advances in Production Engineering \& Management, 13(1), 18-30. https://doi.org/10.14743/apem2018.1.270
[2] Simunovic, G., Simunovic, K., \& Saric T. (2013). Modelling and Simulation of Surface Roughness in Face Milling. International Journal of Simulation Modelling, 12(3), 141153. http://dx.doi.org/10.2507/IJSIMM12(3)1.219

[3] Hoang, T.D., Nguyen, N.T., Tran, D.Q., \& Nguyen, V.T. (2019). Cutting Forces and Surface Roughness in FaceMilling of SKD61 Hard Steel, Strojniski vestnik-Journal of Mechanical Engineering, 65(6), 375-385. https://doi.org/10.5545/sv-jme.2019.6057

[4] Saric T., Simunovic G., Simunovic K., \& Svalina I. (2016). Estimation of Machining Time for CNC Manufacturing Using Neural Computing, International Journal of Simulation Modelling, 15(4), 663-675. https://doi.org/10.2507/IJSIMM15(4)7.359

[5] Ghani, A. J., Choudhury, A. I., \& Hassan, H. H. (2004). Application of Taguchi method in the optimization of end milling parameters. Journal of Materials Processing Technology, 145(1), 84-92. https://doi.org/10.1016/S0924-0136(03)00865-3

[6] Zhang, J. Z., Chen, J. C., \& Kirby, E. D. (2007). Surface roughness optimization in an end-milling operation using the Taguchi design method. Journal of Materials Processing Technology, 184(1-3), 233-239. https://doi.org/10.1016/j.jmatprotec.2006.11.029

[7] Kivak, T. (2014). Optimization of surface roughness and flank wear using the Taguchi method in milling of Hadfield steel with PVD and CVD coated inserts. Measurement, 50, 19-28. https://doi.org/10.1016/j.measurement.2013.12.017

[8] Chang, C. K. \& Lu, H. S. (2007). Design optimization of cutting parameters for side milling operations with multiple performance characteristics. The International Journal of Advanced Manufacturing Technology, 32(1-2), 18-26. https://doi.org/10.1007/s00170-005-0313-5

[9] Tsao, C. C. (2009). Grey-Taguchi method to optimize the milling parameters of aluminum alloy. International Journal of Advanced Manufacturing Technology, 40(1-2), 41-48. https://doi.org/10.1007/s00170-007-1314-3

[10] Gopalsamy, B. M, Mondal, B., \& Ghosh, S. (2009). Optimisation of machining parameters for hard machining: grey relational theory approach and ANOVA. International Journal of Advanced Manufacturing Technology, 45, 10681086. https://doi.org/10.1007/s00170-009-2054-3

[11] Lu, H. S., Chang, C. K., Hwang, N. C., \& Chung, C. T. (2009). Grey relational analysis coupled with principal component analysis for optimization design of the cutting parameters in high-speed end milling. Journal of Materials Processing Technology, 209(8), 3808-3817. https://doi.org/10.1016/j.jmatprotec.2008.08.030

[12] Yan, J. \& Li, L. (2013). Multi-objective optimization of milling parameters - the trade-offs between energy, production rate and cutting quality. Journal of Cleaner Production, 52, 462-471. https://doi.org/10.1016/j.jclepro.2013.02.030

[13] Kant, G. \& Sangwan, K. S. (2014). Prediction and optimization of machining parameters for minimizing power consumption and surface roughness in machining. Journal of Cleaner Production, 83, 151-164. https://doi.org/10.1016/j.jclepro.2014.07.073

[14] Shi, K., Zhang, D., \& Ren, J. (2015). Optimization of process parameters for surface roughness and microhardness in dry milling of magnesium alloy using Taguchi with grey relational analysis. The International Journal of Advanced Manufacturing Technology, 81(1-4), 645-651. https://doi.org/10.1007/s00170-015-7218-8

[15] Varghese, V., Ramesh, M. R., \& Chakradhar, D. (2018). Experimental investigation and optimization of machining parameters for sustainable machining. Materials and Manufacturing Processes, 33(16), 1782-1792. https://doi.org/10.1080/10426914.2018.1476760 
[16] Palanisamy, P., Rajendran, I., \& Shanmugasundaram, S. (2007). Optimization of machining parameters using genetic algorithm and experimental validation for end-milling operations. International Journal of Advanced Manufacturing Technology, 32(7-8), 644-655. https://doi.org/10.1007/s00170-005-0384-3

[17] Zain, A. M., Haron H., \& Sharif, S. (2010). Application of GA to optimize cutting conditions for minimizing surface roughness in end milling machining process. Expert Systems with Applications, 37(6), 4650-4659. https://doi.org/10.1016/j.eswa.2009.12.043

[18] Li, J., Lu, Y., Zhao, H., Li, P., \& Yao, Y. (2014). Optimization of cutting parameters for energy saving. International Journal of Advanced Manufacturing Technology, 70(1-4), 117-124. https://doi.org/10.1007/s00170-013-5227-z

[19] Li, J., Yang, X., Ren, C., Chen, G., \& Wang, Y. (2015). Multiobjective optimization of cutting parameters in Ti-6Al$4 \mathrm{~V}$ milling process using nondominated sorting genetic algorithm-II. The International Journal of Advanced Manufacturing Technology, 76(5-8), 941-953. https://doi.org/10.1007/s00170-014-6311-8

[20] Zhang, C., Li, W., Jiang, P., \& Gu, P. (2016). Experimental investigation and multi-objective optimization approach for low-carbon milling operation of aluminum. Proceedings of the Institution of Mechanical Engineers, Part C: Journal of Mechanical Engineering Science, 231(15), 2753-2772. https://doi.org/10.1177/0954406216640574

[21] Zhang, H., Deng, Z., Fu, Y., Lv, L., \& Yan, C. (2017). A process parameters optimization method of multi-pass dry milling for high efficiency, low energy and low carbon emissions. Journal of Cleaner Production, 148, 174-184. https://doi.org/10.1016/j.jclepro.2017.01.077

[22] Zhang, H., Deng, Z., Fu, Y., Wan, L., \& Liu, W. (2017). Optimization of process parameters for minimum energy consumption based on cutting specific energy consumption. Journal of Cleaner Production, 166, 1407-1414. https://doi.org/10.1016/j.jclepro.2017.08.022

[23] Tandon, V., El-Mounayri, H., \& Kishawy, H. (2002). NC end milling optimization using evolutionary computation. International Journal of Machine Tools and Manufacture, 42(5), 595-605. https://doi.org/10.1016/S0890-6955(01)00151-1

[24] Yang, W., Guo, Y., \& Liao, W. (2011). Multi-objective optimization of multi-pass face milling using particle swarm intelligence. International Journal of Advanced Manufacturing Technology, 56(5-8), 429-443. https://doi.org/10.1007/s00170-011-3187-8

[25] Raja, S. B. \& Baskar, N. (2012), Application of Particle Swarm Optimization technique for achieving desired milled surface roughness in minimum machining time. Expert Systems with Applications, 39(5), 5682-5989. https://doi.org/10.1016/j.eswa.2011.11.110

[26] Li, C., Chen, X., Tang, Y., \& Li, L. (2017). Selection of optimum parameters in multi-pass face milling for maximum energy efficiency and minimum production cost. Journal of Cleaner Production, 140, 1805-1818. https://doi.org/10.1016/j.jclepro.2016.07.086

[27] Rao, R. V. \& Pawar, P.J. (2010). Parameter optimization of a multi-pass milling process using non-traditional optimization algorithms. Applied Soft Computing, 10(2), 445-456. https://doi.org/10.1016/j.asoc.2009.08.007

[28] Gao, S., Pang, S., Jiao, L., Yan, P., Luo, Z., Yi, J., \&Wang, $X$. (2017). Research on specific cutting energy and parameter optimization in micro-milling of heat-resistant stainless steel. The International Journal of Advanced Manufacturing Technology, 89(1-4), 191-205. https://doi.org/10.1007/s00170-016-9062-x

[29] Taguchi, G. (1990). Introduction to quality engineering. McGraw-Hill.
[30] Deng, J.L. (1989). Introduction to grey system. The Journal of Grey System, 1(1), 1-24.

[31] Pearson, K. (1901). On lines and planes of closest fit to systems of points in space. Philosophical Magazine, 2(6), 559-572. https://doi.org/10.1080/14786440109462720

\section{Contact information:}

Đorđe ČIČA, PhD, Professor

(Corresponding author)

Univeristy of Banja Luka,

Faculty of Mechanical Engineering,

Stepe Stepanovića 71 ,

78000 Banja Luka, Bosnia and Herzegovina

E-mail: djordje.cica@mf.unibl.org

\section{Halil CALISKAN, PhD}

Ozaylar Machinery Industry,

Ankara, Turkey

E-mail: halilcaliskan06@yahoo.com

\section{Peter PANJAN, PhD}

Jožef Stefan Institute

Jamova 39, 1000 Ljubljana, Slovenia

E-mail: peter.panjan@ijs.s

\section{Davorin KRAMAR, PhD, Professor}

Univeristy of Ljubljana, Faculty of Mechanical Engineering,

Aškerčeva 6, 1000 Ljubljana, Slovenia

E-mail: davorin.kramar@fs.uni-lj.si 